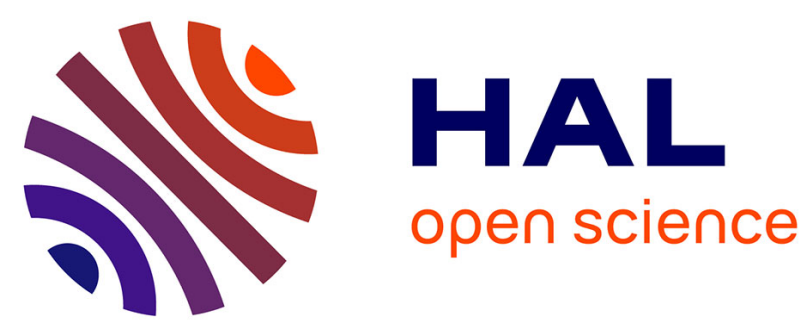

\title{
Monitoring of $\mathrm{SiC}$ Deposition in an Industrial CVI/CVD Reactor by In-Situ FTIR Spectroscopy
}

\author{
H. Mosebach, V. Hopfe, M. Erhard, M. Meyer
}

\section{To cite this version:}

H. Mosebach, V. Hopfe, M. Erhard, M. Meyer. Monitoring of SiC Deposition in an Industrial CVI/CVD Reactor by In-Situ FTIR Spectroscopy. Journal de Physique IV Proceedings, 1995, 05 (C5), pp.C5-97-C5-104. 10.1051/jphyscol:1995509 . jpa-00253765

\section{HAL Id: jpa-00253765 https://hal.science/jpa-00253765}

Submitted on 1 Jan 1995

HAL is a multi-disciplinary open access archive for the deposit and dissemination of scientific research documents, whether they are published or not. The documents may come from teaching and research institutions in France or abroad, or from public or private research centers.
L'archive ouverte pluridisciplinaire HAL, est destinée au dépôt et à la diffusion de documents scientifiques de niveau recherche, publiés ou non, émanant des établissements d'enseignement et de recherche français ou étrangers, des laboratoires publics ou privés. 


\title{
Monitoring of $\mathrm{SiC}$ Deposition in an Industrial CVI/CVD Reactor by In-Situ FTIR Spectroscopy
}

\author{
H. Mosebach, V. Hopfe*, M. Erhard and M. Meyer** \\ Kayser-Threde GmbH, Wolfratshauser Str. 48, 81379 München, Germany \\ * Fraunhofer-Institut für Werkstoffphysik und Schichttechnologie, PF 16, 01171 Dresden, Germany \\ ** Daimler-Benz AG, Zentrales Werkstofflabor, 81663 München, Germany
}

\begin{abstract}
A FTIR based method was developed for in-situ monitoring the gas phase chemistry in the reaction chamber of technological scale CVICVD reactors. Using methyltrichlorosilane (MTS) as SiC precursor, several gaseous species could be detected including $\mathrm{MTS}, \mathrm{SiCl}_{2}$, $\left(\mathrm{SiCl}_{3}\right)_{\mathrm{n}=1,2}, \mathrm{SiCl}_{4}, \mathrm{HSiCl}_{3}, \mathrm{CH}_{4}, \mathrm{CH}_{3} \mathrm{Cl}$ and $\mathrm{HCl}$ which, consequently, can be monitored simultaneously. First attempts have been established for deriving arbitrary and absolute concentrations of species from emission spectra. The determined composition of the reaction mixture supports recent theoretical results of kinetic modelling. Using the established technique, several runs have been monitored within the SiC-CVI/CVD reactor at different stages of deposition. Unexspectedly strong variations of concentrations of most of the gaseous species have been detected whose reason is not fully clear yet. These technique will be a key element in establishing a closed loop process control.
\end{abstract}

\section{INTRODUCTION}

Chemical vapour deposition (CVD) as well as infiltration (CVI) are premier techniques for the production of fibre reinforced ceramic composite materials. Fibre woven structures (preforms) are coated/impregnated in a hot wall reactor by pyrolysing a mixture of precursor gases, which precipitates the ceramic material within the pores of the preform. The techniques are attractive for forming composites with superiour mechanical properties and high thermal stability, but the long processing time (CVI) of typically some days up to weeks and the poor run-to-run reproducibility still limit the applicability of that technology.

In order to maximize the potential of CVD technology, flexible, high yield processes are required. Critical in achieving this potential is an effective degree of process control. To date this has largely been ignored due to the technical challenges posed. These of ten include corrosive atmospheres, particulates, hot environments, vibrations, difficultics in establishing steady states, measurement (e.g. sensitivity) and response time issues. Reactor operation in an open loop with optimization of process parameters based on characterization of post processed materials is the conventional way of operation. In CVI e.g., the change in precursor concentration leads to uncontrolled variations of the pore filling rate, and consequently, to unwanted closing of unfilled pores. Thus, the use of a sensor system for in-situ monitoring is a key element for improving control of CVD/CVI processes.

Although the deposition and infiltration techniques are used on a technological scale, the underlying chemistry is not completely understood $[1,2]$. Using extractive techniques, gas phase reactions governing CVD related processes have been studied extensively during the past fifteen years by means of mass spectrometry and FTIR. These methods suffer from having no capability of detecting intermediates and thus, give no complete look into the chemistry. This drawhack can be overcome by in-situ technigues, in which opticit methods are most suitable. Many different spectroscopic methods have been used, particularly for gas-phase reaction studies to understand the mechanisms and kinetics of 
CVI/CVD and chemically based physical vapour deposition [3-8]. First attempts were carried out to investigate surface processes in CVD systems by in-situ FTIR reflection and emission spectroscopy [9]. Amongst all the different spectroscopic techniques the FTIR method seems to be one of the most favourable for in-situ monitoring because of important advantages like multicomponent capabililty, the common application of emission, transmission and even reflection spectroscopy, and finally the low operating costs.

Most of the above mentioned research was focussed on basic problems and measurements in specially designed lab reactors. So far, only two projects are known, in which FTIR in-situ monitoring was applied to prototype production plants. In one group the ability of film (ferroelectric films) reflectance and radiance measurements during MOCVD was demonstrated [8]. In previous papers the authors of this paper presented the application of FTIR in-situ monitoring to a full scale SiC CVI/CVD production plant, where the feasibility of FTIR in-situ monitoring could be verified and important results on the $\mathrm{SiC}$ chemistry could be achieved when using methyltrichlorosilane (MTS) as precursor $[2,11]$.

It is the goal of this work to establish in-situ FTIR monitoring methods as leading components for a future process control line on CVD/CVI production scale reactors. This paper presents, after a short outline of the hardware adaption, the chemistry involved, and the spectrometric aspects of the analysis. some very recent not fully exploited results of in-situ monitoring of CVD/CVI runs at the DB plant and a first attempt at quantification of the precursor gas concentration.

\section{EXPERIMENTAL AND ANALYTICAL SYSTEM}

The FTIR system K300 was used as the spectrometric device for analysis. This instrument was originally designed for open path environmental monitoring consisting of a collecting telescope, which lecds the IR radiation coming in from a remote radiation source (either an artificial source for transmission measurements or a hot plume) into the spectrometer. The K300 system has a maximum, apodized. spectral resolution of $0.1 \mathrm{~cm}^{-1}$ and is equipped with a MCT detector ranging from $450-3500 \mathrm{~cm}^{-1}$ wavenumber. With this detector the particularly interesting region of the stretching and bending vibrations of the chlorinated silanes was covered.

For installation at the DB CVD/CVI reactor the telescope of the $\mathrm{K} 300$ was removed and replaced hy it new optical interface connected to the reactor, see Fig. 1.

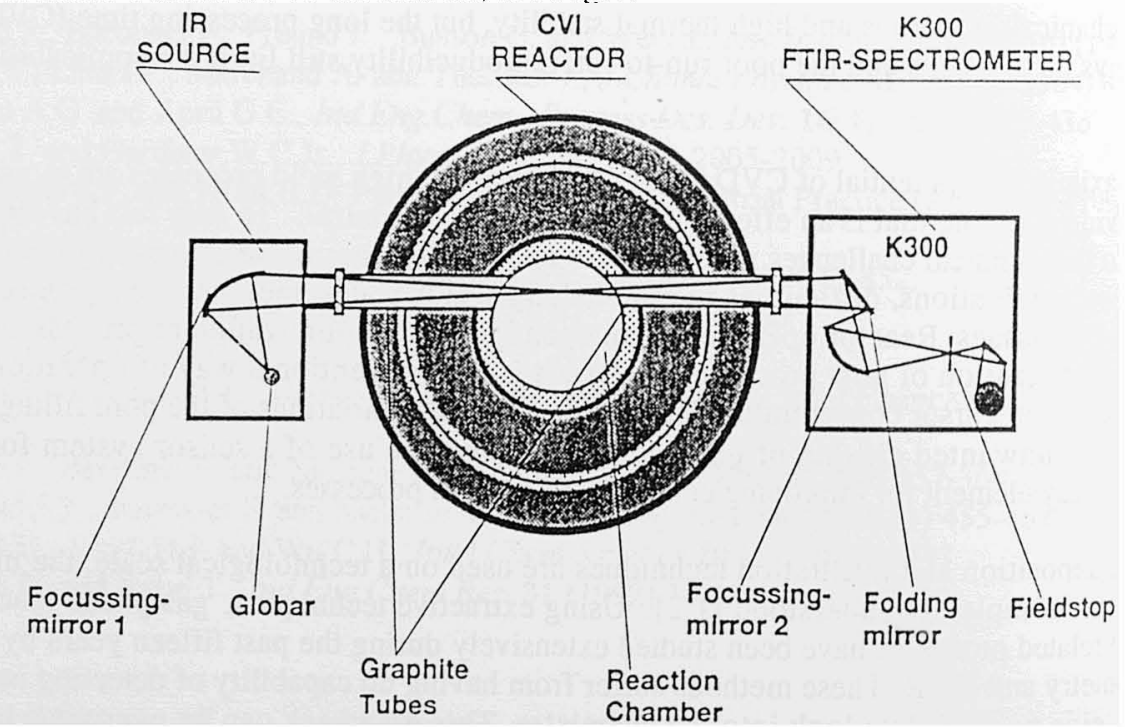

Fig. 1: Schematic diagram of FTIR and CVVCYI) reactor system. 
Two tubes made of graphite were implemented on either side of the hot zone of the reactor, which were aligned on-axis to the K300 line of sight. The tube opposite the spectrometer was designed for collimating the IR radiation from an external infrared source into the reaction zone in case of transmission measurements. In case of emission measurements this port will be left open to have a low background radiation. The process dependent IR radiation to be analyzed by the spectrometer was fed into the $\mathrm{K} 300$ via the second tube. The outer ends of the tubes were closed by IR transparent $\mathrm{KBr}$ windows being purged with argon in order to avoid coverage by reaction by-products.

By means of comprehensive test measurements the feasibility of the analytical method could be demonstrated, algorithms for the interpretation of IR spectra were developed and better understanding of the $\mathrm{SiC}$ chemistry was achieved [2]. After a longer period of optimization of the measuring configuration the best results have been achieved by emission spectroscopy [11]. Test runs were made in a temperature range from $670 \mathrm{~K}$ to $1320 \mathrm{~K}$. Beside MTS also other compounds like methane and tetrachlorosilane were used as input gases. Several gaseous species have been detected, including $\mathrm{MTS}, \mathrm{SiCl}_{2}$, $\left(\mathrm{SiCl}_{3}\right)_{\mathrm{n}=1,2}, \mathrm{SiCl}_{4}, \mathrm{HSiCl}_{3}, \mathrm{H}_{2} \mathrm{SiCl}_{2}, \mathrm{CH}_{4}, \mathrm{CH}_{3} \mathrm{Cl}$ and $\mathrm{HCl}$ (Fig.2) also possible indications for $\mathrm{CH}_{3}$ radicals and $\mathrm{SiC}$ clusters.

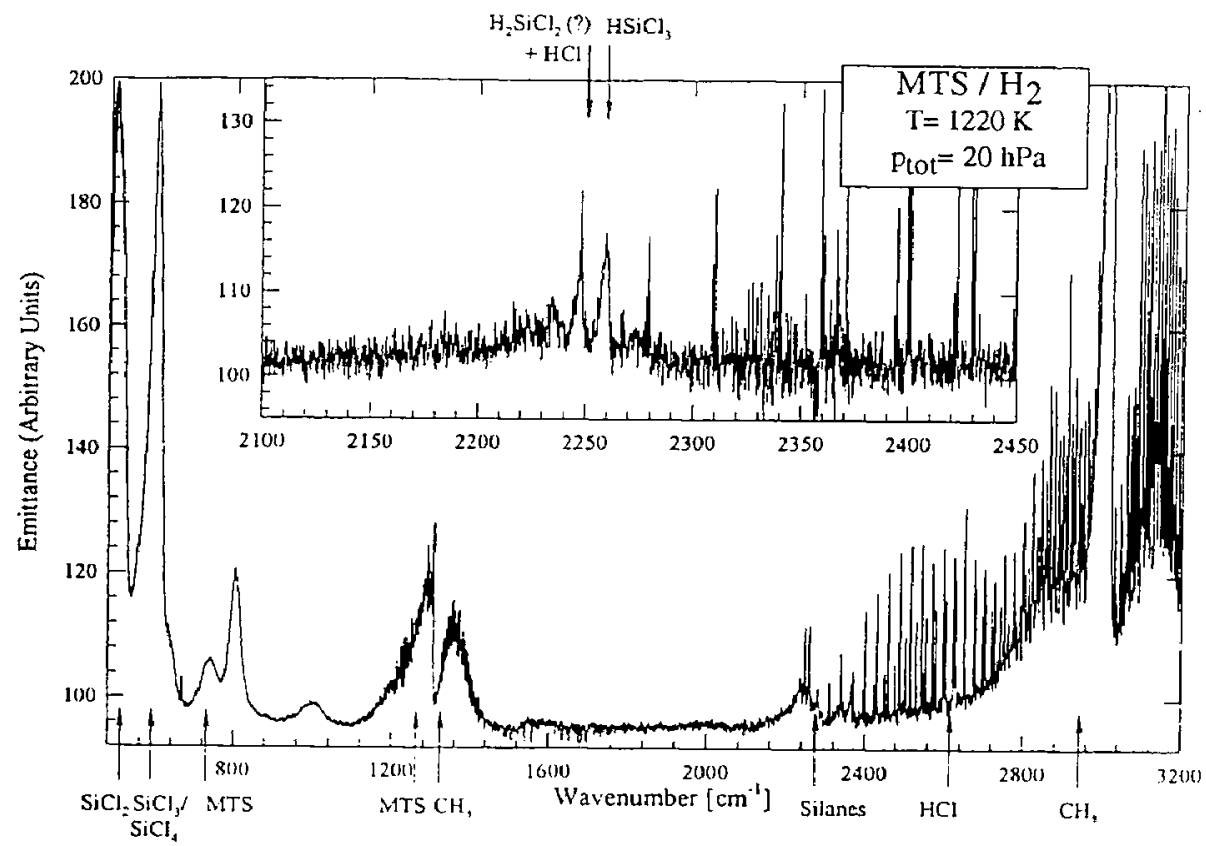

Fig. 2: FTrR monitoring of a typical CVl run: Emission spectrum of $\mathrm{MTS} / \mathrm{H}_{2}$.

The CVI/CVD runs at the DB plant were normally performed at process temperatures between $1170 \mathrm{~K}$ and $1470 \mathrm{~K}$ under reduced pressure (typically $10-50 \mathrm{hPa}$ ) with a reaction mixture of $\mathrm{MTS}$ and $\mathrm{H}_{2}$. Fig. 2 illustrates observed emittance bands detected during a typical CVI run.

A specific problem of the spectroscopy of reactive gas mixtures at high temperatures is the quantification of the results, i.e. to estimate concentrations of the species from band intensities, since it was found that most of the mentioned compounds are not stable at process temperatures, not even $\mathrm{SiCl}_{4}$. Therefore, it is very difficult at operation temperature to prepare a sample for analysis with known concentration of the species of interest, but this is essential for quantitative analysis.

In order o extract concentration proportional quantities from spectra, reterence measurenents must be pertorned. This can he done by urning onl al intervalls, the incoming precursor gas flow while kee- 
ping all other parameters of the whole system unchanged. The background radiation, originating from the hot walls, has a blackbody characteristic which makes them useful for estimating apparent emittance quantities by forming the ratio of the sample and reference spectra. Furtheron, spurious effects in the IR single beam spectra are removed by this procedure so all signatures resulting from gaseous species in the CVI reaction zone. The observed apparent emittance values are proportional to the concentrations, a value of 100 means that concentration was at or below the detection limit. This simple but very convenient calibration method is useful for estimating concentration changes of individual species.

\section{ONLINE MONTTORINGWTTH IN-SITU FTIR SPECTROMETRY 3.1 Monitoring an SiC - FCVI Run}

The SiC forced flow infiltration (FCVI) of a demonstrator nozzle at the DB reactor was on-line monitored by spectrometric analysis with the $\mathrm{K} 300$. The process parameters are listed in Tab. 1 :

Table 1: Parameters of the SiC. CVI/CVD processes on the demonstrator nozzle.

\section{Process type}

MTS flow rate (liquid)

$\mathrm{H}_{2}$ flow rate

Carrier gas

Reaction temperature

Total pressure behind nozzle

Pressure
Forced flow CVI (FCVD)

$3.7 \mathrm{mV} / \mathrm{min}$

$7.5 \mathrm{~V} / \mathrm{min}$

Ar

$1220 \mathrm{~K}$

$50 \mathrm{hPa}$

varying between $10-20 \mathrm{hPa}$
CVD

$17 \mathrm{ml} / \mathrm{min}$

$10 \mathrm{l} / \mathrm{min}$

Ar

$1470 \mathrm{~K}$

$50 \mathrm{hPa}$

The following compounds were clearly detected: $\mathrm{MTS}, \mathrm{SiCl}_{2}, \mathrm{SiCl}_{4},\left(\mathrm{SiCl}_{3}\right)_{\mathrm{n}=1,2}, \mathrm{SiHCl}_{3}$, a chlorosilo$x$ anes band, $\mathrm{CH}_{3} \mathrm{Cl}, \mathrm{HCl}$ and $\mathrm{CH}_{4}$. Next, realtime measurements with different time scale have been performed: (i) with $25 \mathrm{~s}$ sampling time over a period of $12 \mathrm{~min}$., and (ii) with $9 \mathrm{~s}$ sampling time over $250 \mathrm{~s}$. Caused by software restrictions in case (ii) the concentration changes of only one species have been followed.

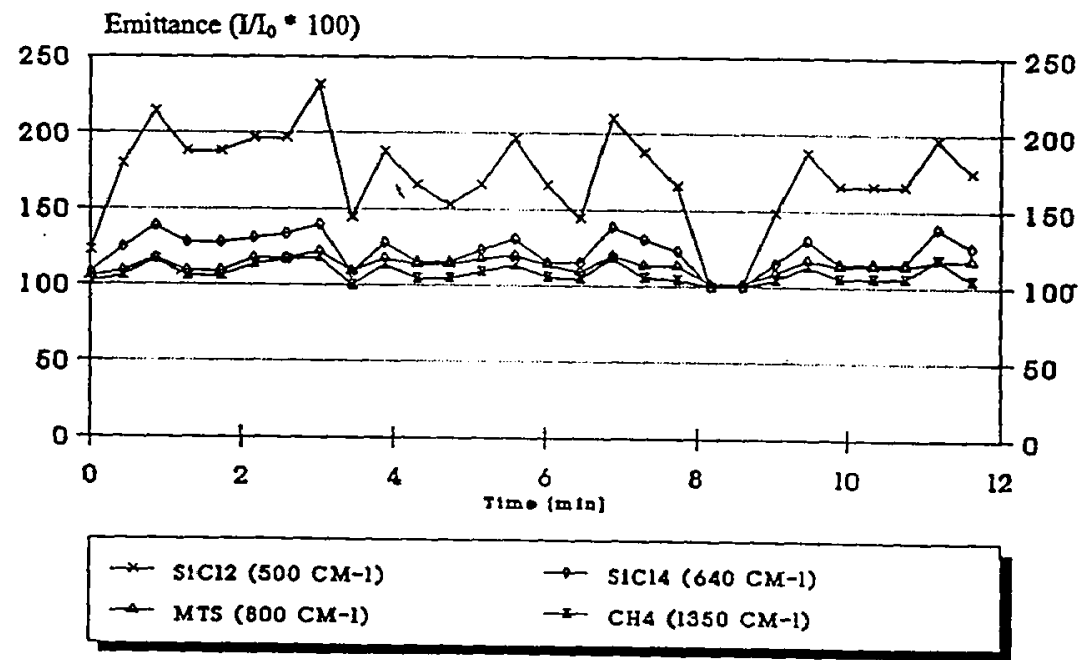

Fig. 3: Time dependence of emittance values of $\mathrm{MTS}, \mathrm{SiCl}_{2}, \mathrm{SiCl}_{4}$ and $\mathrm{CH}_{4}$. 
Fig. 3 shows the time dependence of the observed emiltance values of the four species $\mathrm{MTS}_{\mathrm{SiCl}}$, $\mathrm{SiCl}_{4}$ and $\mathrm{CH}_{4}$. These compounds along with $\mathrm{HCl}$ and $\left(\mathrm{SiCl}_{3}\right)_{n=1,2}$ were the dominating features in obtained spectra. The concentrations of these four species significantly changed with time and were, as a striking result, strongly correlated. Also with higher time resolution these concentration changes are clearly detectable, see Fig. 4. The pressure difference behind and in front of the nozzle also varied significantly (between 10 and $20 \mathrm{hPa}$ ) which have been correlated with the change in concentration of the detected species. After the CVI run a leakage in the high pressure region was found, which possibly gave rise to the pressure fluctuations.

During start-up of the CVI run, the K300 monitoring was carried out with the shortest possible sampling time, which at the desired resolution of $1 \mathrm{~cm}^{-1}$ is around 2 seconds. This was done for inspecting the initial phase of the CVI process. It was found that typical emittance values were observed after about 20 seconds. The presently available software does not allow this time dependence to be registered.

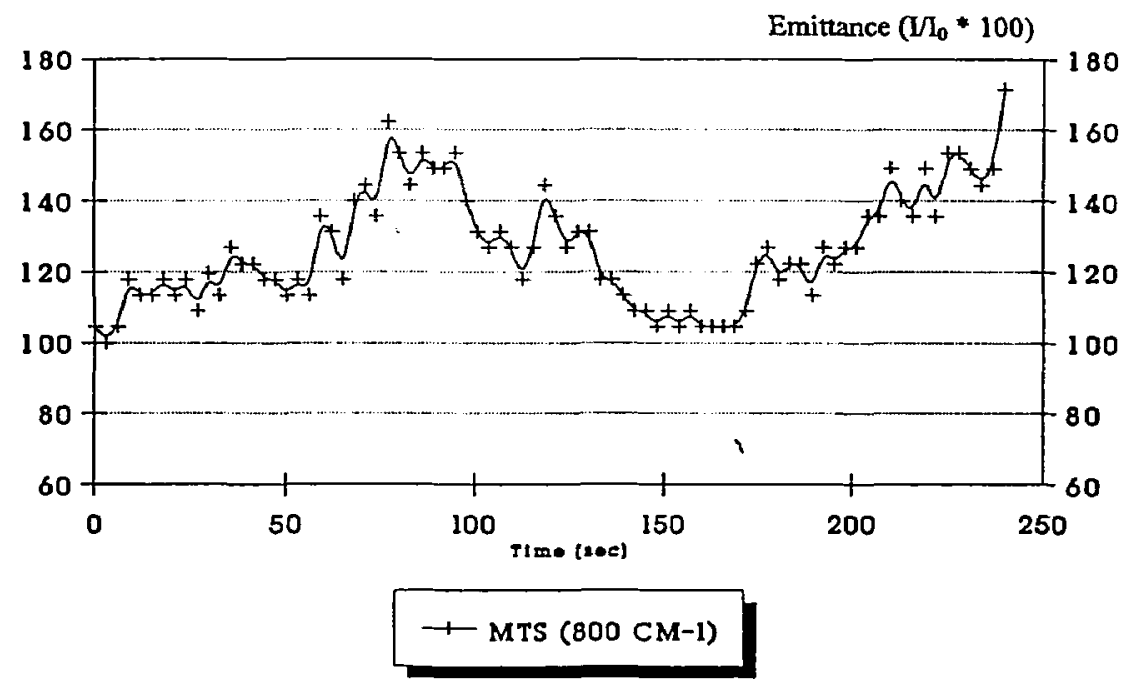

Fig. 4: Time dependence of emittances for MTS (curve has beten fitted by spline function interpolation).

\subsection{Monitoring a SiC CVD Run}

In a second step the same demonstrator nozzle was encapsulated with SiC. This CVD run was also monitored in-situ by realtime spectrometric analysis with the K300. For process parameters see Tab.1.

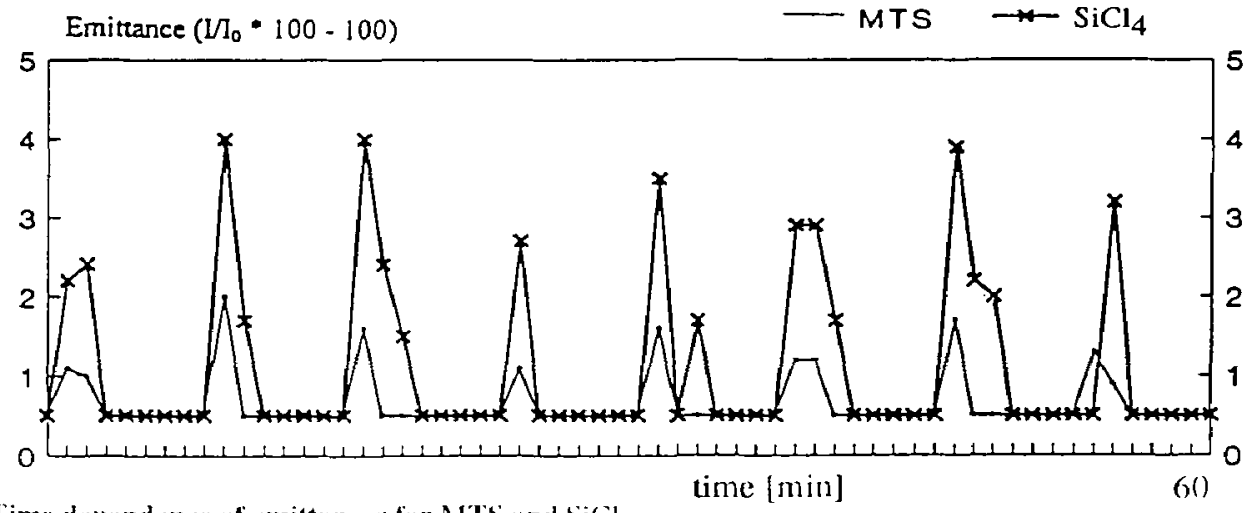

Fig. 5: Time dependence of emittances for MTS and $\mathrm{SiCl}_{4}$. 
In contrast to the CVI runs only six species have been detected: $\mathrm{MTS}, \mathrm{SiCl}_{2}, \mathrm{SiCl}_{4}, \mathrm{HCl}, \mathrm{CH}_{4}$ and chlorosilanes. In addition, the observed emittance values were considerably lower than those measured during the infiltration run, which might be caused by higher reaction rates at higher temperatures.

Fig. 5 and 6 show the time dependence of the $\mathrm{SiCl}_{2}, \mathrm{SiCl}_{4}$ and $\mathrm{MTS}$ emittance values. Despite the flows of MTS and $\mathrm{H}_{2}$ were kept constant, periodical emittance peaks of MTS were observed. There is a strong correlation between these maxima and the $\mathrm{SiCl}_{4}$ peaks. On the contrary, there seems to be less significant correlation between $\mathrm{MTS}$ and $\mathrm{SiCl}_{2}$ emittances. The minimum emittance values in these plots indicate the actual detection limits.

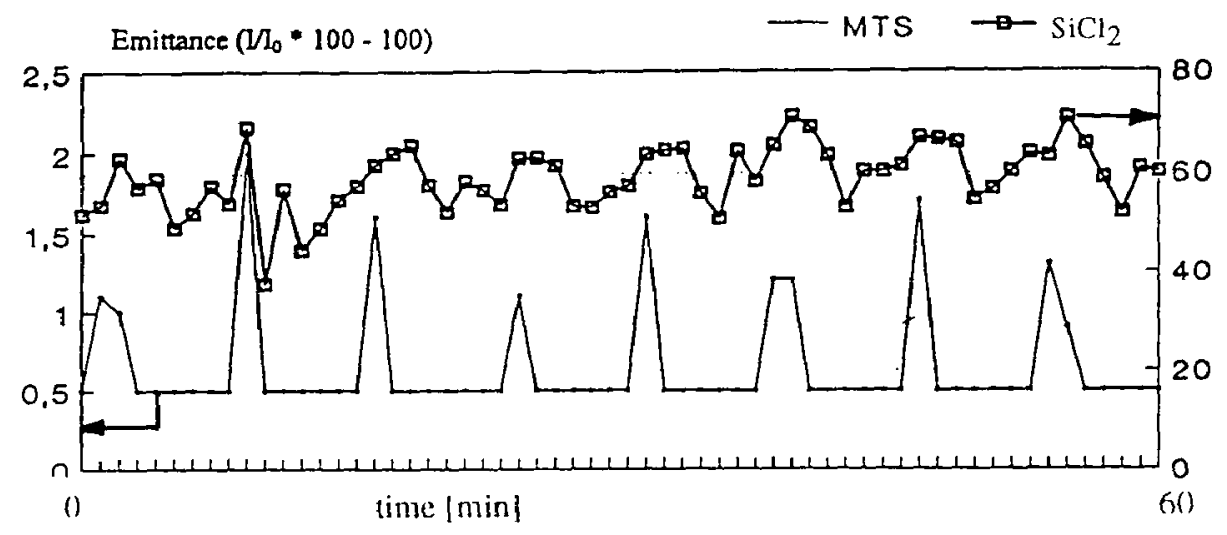

Fig. 6: Time dependence of emittances for $\mathrm{MTS}_{\text {and }} \mathrm{SiCl}_{2}$.

\section{ESTIMATION OF CONCENTRATION}

Caused by a lack of reference spectra for intensity calibration at working temperature, the quantitative spectroscopy is very difficult. The variation of concentration can be estimated by taking into account the following assumptions: (i)the absolute emittance $E$ of the gaseous species is $E<1$. and (ii) the background radiation, as well as (iii)the reabsorption are negligible. With the additional assumption of (iv)negligible changes in temperature dependance of the integrated band intensity (constant oscillator strength), also the absolute concentration of MTS can be derived.

The above stated assumptions (i) and (ii) have been verified by measuring the radiation fluxes within the spectrometer-reactor configuration using a calibrated blackbody source. Reabsorption phenomena (iii) have been checked by comparing the band contour of the $\mathrm{HCl}$ rotational/vibrational band with simulated spectra.

For estimating concentration changes two data processing procedures have been developed:

- Estimation of maximum intensity (baseline method) of selected bands having low overlap with bands of other species.

- Estimation of weighting factors by balancing the ratio of two spectra within the region of a selected band of the component to be measured. This is a better attempt for partially overlapping bands of different species.

For estimating the absolute concentration of MTS a multi-sup concept was established. It is hased on a set of reference spectra being neasured as a function ol temperature in an incre atmosphere: 
(1) Selecting a MTS emission with a low temperature dependence of the integrated band intensity and band position: band at $803 \mathrm{~cm}^{-1}$.

(2) Using the spectrum of pure MTS at $870 \mathrm{~K}$ as a reference where no decay products have been detected, the corresponding absolute concentration (partial pressure) is derived from control of the precursor feed system.

(3) Calculating the MTS concentration (or partial pressure) at higher temperatures by the spectra balancing method (see above)

The results are summerized in Tab. 3 for some reaction conditions.

Table. 3: Concentration estimates of individual gaseous species.

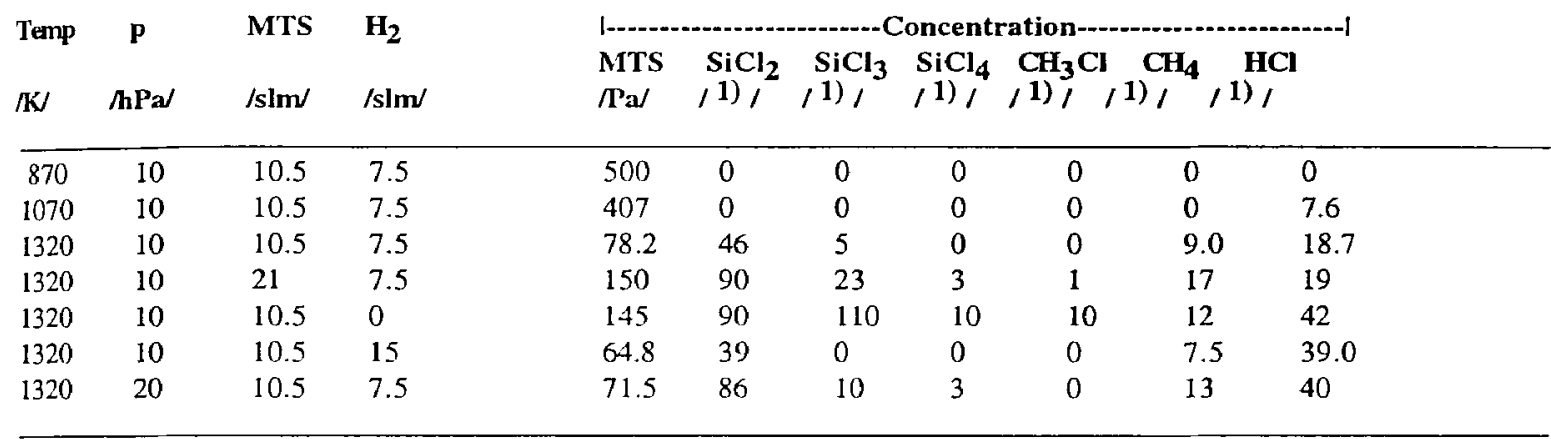

1) arbitrary units

\section{KINETICS OF THE MTS DECAY}

The estimated concentrations of MTS and some other species $\left(\mathrm{CH}_{4}, \mathrm{CH}_{3} \mathrm{Cl}, \mathrm{Tab} .3\right)$ are much higher than the equilibrium concentration ( $\vee f$. Tab.1 in [2]) which gives evidence for a kinetically controlled reaction. Without being able within the framework of this paper to discuss the kinetics of the MTS pyrolysis reactions in more detail, it might be very useful to compare the results given above with some recent theoretical attempts [1]. Supported by RRKM calculations the most ablindant reaction channels of the primary decay of MTS are given by equation (1) - (3). Reaction (4) is less probable because of its higher activation entropy [10].

$$
\begin{array}{lllll}
\mathrm{CH}_{3} \mathrm{SiCl}_{3} & --> & \mathrm{CH}_{3} & + & \mathrm{SiCl}_{3} \\
\mathrm{CH}_{3} \mathrm{SiCl}_{3} & --> & \mathrm{CH}_{2} \mathrm{SiCl}_{3} & + & \mathrm{H} \\
\mathrm{Cl}_{3} \mathrm{SiCl}_{3} & --> & \mathrm{H}_{2} \mathrm{C}=\mathrm{SiCl}_{2} & + & \mathrm{HCl} \\
\mathrm{CH}_{3} \mathrm{SiCl}_{3} & --> & \mathrm{SiCl}_{2} & + & \mathrm{CH}_{3} \mathrm{Cl}
\end{array}
$$

The reaction rate of the primary reaction increases rapidly with total pressure, e. from $1 \mathrm{kPa}$ to 100$)$ $\mathrm{kPa}$ by a factor of 20 . This is accompanied by reaction branching where the $\mathrm{C}-\mathrm{H}$ bond cleavage (eq. 2) becomes more probable. The products of the primary decay can undergo several consecutive reaction. In a hydrogen rich mixture, being typical for the SiC-CVI/CVD process, equation (5)-(6), for instance, are dominating but in an "inert" atmosphere the reaction paths (7)-(8) are more probable.

\begin{tabular}{|c|c|c|c|c|c|c|c|}
\hline $\mathrm{CH}_{3}$ & + & $\mathrm{H}_{2}$ & $\cdots>$ & $\mathrm{CH}_{4}$ & + & $\mathrm{H}$ & (5) \\
\hline $\mathrm{SiCl}_{3}$ & + & $\mathrm{H}_{2}$ & $\cdots>$ & $\mathrm{ISiCl}_{3}$ & + & $\mathrm{H}$ & (6) \\
\hline $\mathrm{SiCl}_{3}$ & + & $\mathrm{CH}_{3}$ & $\cdots>$ & $\mathrm{SiCl}_{2}$ & + & $\mathrm{CH}_{3} \mathrm{Cl}$ & (7) \\
\hline $\mathrm{SiCl}_{3}$ & & & $-->$ & $\mathrm{SiCl}_{2}$ & + & $\mathrm{Cl}$ & (8) \\
\hline
\end{tabular}

The most important gaseous species for the deposition reaction are expected to be: $\mathrm{SiCl}_{2}, \mathrm{CH}_{4}$ and $\mathrm{HSiCl}_{3}[10]$. 
In comparing the kinetic model with both the spectroscopic results and the thermodynamic estimates [2], the following conclusions can be drawn:

(i ) Most of the species proposed by kinetic theory have been identified in the experiments. Because of the variety of reaction channels it cannot be distinguished whether some key species, as $\mathrm{SiCl}_{2}$ and $\mathrm{CH}_{3} \mathrm{Cl}$, are arising from primary bond cleavage or from secondary reactions.

(ii) The CVI process is kinetically controlled. This is suggested by the observation that the concentrations of $\mathrm{CH}_{3} \mathrm{SiCl}_{3}, \mathrm{CH}_{4}$ and $\mathrm{CH}_{3} \mathrm{Cl}$ are some orders higher and those of $\mathrm{SiCl}_{4}$ and $\mathrm{HSiCl}_{3}$ are lower than derived from thermodynamic equilibrium.

(iii) The MTS decay rate increases with total pressure, and the distribution of species changes.

\section{CONCLUSION AND OUTLOOK}

The FTIR method presented in this paper is well suited for in-situ monitoring the gas atmosphere in the reaction chamber of technological scale CVI/CVD reactors. More than ten gaseous species and intermediates have been identified and can be monitored simultaneously. Using the established technique, several CVI/CVD runs have been followed online. The performance has been demonstrated by multicomponent measurements with a time resolution down to $2 \mathrm{~s}$. Unexspectedly strong variations of concentrations of most of the gaseous species have been detected whose reason is not fully clear yet.

The determined composition of the reaction mixture supports recent theoretical results of kinetic modelling. Together with the advanced in-situ FTIR monitoring capabilities established here, this approach will serve as a starting point for developing a closed loop control of CVD based coating techniques. Related work is underway.

\section{Acknowledgements}

This work was funded by the Commission of the European Community (CEC) within the BRITE-EURAM research programme under contract number BREU-CT91-0447.

The CVI/CVD plant at Daimler-Benz AG was built by Archer Technicoat Ltd, UK. Archer also realized the mechanical modifications of the reactor for FTIR adaption with the K300.

\section{References}

[1] Osterheld T.H., Allendorf M.D. and Melius C.F., Sandia Report SAN93-8576.UC-401, (1993).

[2] Hopfe V., Mosebach H., Erhard M., Meyer M., J. Molec. Structure 347(1995) 331.

[3] Ho P. and Breiland W.G., Appl. Phys. Lett., 43 (1983) 125.

[4] Hanabusa M. and Kikushi H., Jpn. J. Appl. Phys., 22 (1983) 11; M. Hanabusa et.al., Springer Series in Chem. Phys., 39 (1984) 197.

[5] Butler J.E., J.Cryst. Growth, 77 (1986) 163.

[6] Cleland T.A. and Hess D.W., J. Vac. Sci. Technol. B, 7 (1989) 35.

[7] Salim S., Lim C.K. and Jensen K.F., SPIE, 2069 (1993) 132.

[8] Farquharson S., Carangelo R.M., HaigisJ.R., MorrisonP.W., SolomonP.R., KirklinP.S. and Van Buskirk P.C., SPIE Proc. on: Optical Methods for Chemical Process Control, Boston, September 1993, p. 2.

[9] Hopfe V., Wagner D., Klobes P., Herzig S. and Marx G., J. Molecular Structure, 217 (1990) 115-130.

[10] Allendorf M.D. and Melius C.F., J. Phys. Chem., 97 (1993) 720.

[11] Mosebach H., Erhard M., Resch M. and Bittner H., SPIE Proc. on "Optical Methods for Chemical Process Control" Boston, USA, Sept. 1993. 